Recebido em 11/2019. Aceito para publicação em 01/2020.

\title{
APLICAÇÃO DO PROCESSO DE FITORREMEDIAÇÃO UTILIZANDO VETIVER (VETIVERIA ZIZANIOIDES (L.) NASH.) NA DESCONTAMINAÇÃO DE SOLOS TROPICAIS CONTAMINADOS POR CHORUME
}

\section{APPLICATION OF THE PHYTOREMEDIATION PROCESS USING VETIVER GRASS (VETIVERIA ZIZANIOIDES (L.) NASH.) FOR THE DECONTAMINATION OF TROPICAL SOILS CONTAMINATED WITH SLURRY FROM SOLID WASTE DEGRADATION}

\author{
Erica Aparecida dos Santos ${ }^{1}$ \\ Thais Luane dos Santos Mariano ${ }^{2}$ \\ Paulo Roxo Barja ${ }^{3}$ \\ Maria Regina de Aquino-Silva ${ }^{4}$
}

\begin{abstract}
Resumo: Um dos contaminantes comuns, geralmente encontrado em áreas de aterro sanitário ou antigos lixões, é o chorume: resíduo líquido de cor escura e forte odor, composto pela degradação de matéria orgânica. Em alguns casos são encontrados metais pesados em sua composição e outros tipos de substâncias que causam contaminação direta do solo e corpos d'água próximos ou subterrâneos. $O$ objetivo deste trabalho foi verificar a eficiência da gramínea Vetiver (Vetiveria zizanioides (L.) Nash.) no processo de fitorremediação em solos tropicais contaminados com chorume proveniente da degradação de resíduos sólidos. Foram realizados testes laboratoriais com o intuito de detectar a eficiência da Vetiver em tratar este solo contaminado e o quanto ela é capaz de absorver as substâncias contaminantes. Foram analisados os parâmetros de Zinco em amostras das raízes, folhagens, solo utilizado para o plantio das mudas de Vetiver e do líquido resultante do processo de lixiviação. Utilizou-se amostras contaminadas e sem contaminação para que obtivesse um comparativo entre os resultados, as quais foram também analisadas estatisticamente. A espécie em estudo, o capim Vetiver (Vetiveria zizanioides (L.) Nash.), ao longo de 45 dias, mostrou-se eficaz no tratamento de solo contaminado, em especial na remoção do metal pesado Zinco. Todavia, considerando que o efluente em questão é um material complexo, de composição altamente diversificada, novas avaliações utilizando o capim Vetiver devem ser estabelecidas a fim de elucidar melhor a utilização deste elemento no tratamento de chorume.
\end{abstract}

Palavras-chave: Vetiver; chorume; solos tropicais; fitorremediação.

\begin{abstract}
One of the common contaminants, usually found in areas of landfill or old trash dumps, is slurry: a liquid residue with dark color and strong odor, originated from the degradation of organic matter. In some cases, heavy metals are found in its composition, besides other types of substances that cause direct contamination of the soil and close or underground water bodies. The purpose of this work was to verify the efficiency of Vetiver grass (Vetiveria zizanioides (L.) Nash.) in the process of phytoremediation in tropical soils contaminated with slurry from solid waste degradation. Laboratory tests were conducted to detect the efficiency of Vetiver in treating this contaminated soil and how much it is able to absorb the contaminating substances. Zinc parameters were analyzed in samples of roots, foliage, the soil used for the planting of Vetiver seedlings and the liquid resulting from the leaching process. Contaminated and decontaminated samples were used to obtain a comparison between the results, which were also analyzed by statistical

\footnotetext{
1 Graduada em Engenharia Ambiental e Sanitária, Mestranda em Bioengenharia, Universidade do Vale do Paraíba, Brasil. Bolsista IGTPAN. E-mail: erica_santos000@hotmail.com.

2 Graduada em Engenharia Ambiental e Sanitária, Universidade do Vale do Paraíba, Brasil. E-mail: thais.luane@yahoo.com.br.

3 Doutor em Física, Professor, Universidade do Vale do Paraíba, Brasil. barja@univap.br.

${ }^{4}$ Doutora em Ciências, Orientadora, Universidade do Vale do Paraíba, Brasil. mregina@univap.br.
} 
methods. After 45 days, the Vetiver grass (Vetiveria zizanioides (L.) Nash.) was proven effective in the treatment of contaminated soil, especially in the removal of the heavy metal Zinc. However, considering that this effluent is a complex material, with a highly diversified composition, new evaluations using Vetiver grass must be established in order to better elucidate the use of this element in the treatment of leachate.

Keywords: Vetiver; slurry; tropical soils; phytoremediation.

\section{INTRODUÇÃO}

A problemática relacionada a áreas contaminadas vem sendo bastante discutida ao longo dos últimos 15 anos, tendo como enfoque as perguntas: como recuperar o solo contaminado? Qual método deve ser utilizado? O método escolhido é de aplicação viável? Neste sentido, uma série de estudos vem sendo realizadas em especial, em solos tropicais (COUTINHO et al, 2015).

A utilização de plantas como elementos remediadores e de estabilização de solos pode ser classificada como de baixo custo e fácil aplicabilidade quando o processo não exige um resultado em curto prazo, uma vez que esse tipo de metodologia necessita de tempo para que haja uma eficácia considerável e que alcance os resultados esperados. Se comparado a grandes obras de bioengenharia, o método apresenta-se como uma boa opção econômica e ambiental (MONTEIRO, 2008).

O solo, uma vez sofrendo interferências antrópicas oriundas de processos industriais ou de contaminação direta por efluentes, torna-se vulnerável e portando sofre alterações que, se não forem mitigadas, tornam-se irreversíveis e prejudiciais a todo o ecossistema do entorno. Neste sentido, uma vez contaminado, o ambiente dever ser tratado de forma a minimizar os níveis de contaminantes e retornar a uma condição adequada (MONTEIRO, 2008).

O Zinco é um elemento químico que se encontra presente nos diferentes ambientes naturais como água e solo sendo um oligonutriente fundamental a vida, uma vez que participa de diversos processos bioquímicos (BARRETO, 2010). Como recurso natural é utilizado na indústria de galvanização, conferindo proteção contra corrosão de peças de aço e ferro da corrosão. Neste sentido, além de ser disponibilizado via processos naturais, a sua presença na natureza pode ocorrer em função de ações antrópicas como descarte inadequado de grandes quantidades deste elemento.

A fitorremediação é uma metodologia que avalia o potencial de descontaminação dos solos contaminados, seja por metais pesados ou algum componente químico (orgânico ou não). O processo de remediação desenvolvido por plantas é caracterizado como remediação natural ou fitorremediação natural, sendo conceitualmente definido como a ação dos microrganismos associados aos indivíduos vegetais para o controle e tratamento do ar, da água e do solo, promovendo uma resposta eficaz a diferentes tipos de contaminação. Um dos fatores a serem observados para a utilização desta metodologia e de espécies com a capacidade de extração de contaminantes é o seu potencial de crescimento, alta produção de biomassa, sistema radicular profundo e fácil 
controle (LEAL et al., 2013), competitividade, vigor e tolerância a poluição (LAMEGO; VIDAL, 2007).

A partir destas premissas, considerando a aplicabilidade e viabilidade do processo, a revisão de literatura reconhece essas características em uma espécie de gramínea, o capim Vetiver (Vetiveria zizanioides L.). Trata-se de uma espécie tropical, capaz de se adaptar as mais diversas condições climáticas. É originária da Índia, estéril, não invasiva e, geralmente, pode ser transferida para um viveiro, visando sua multiplicação, com cerca de 3 meses. Para utilização em taludes e em áreas contaminadas, devem ser cultivadas com mudas próximas para que as raízes criem estabilidade e barreiras internas rígidas que conduzirão o fluxo de água. Os sedimentos oriundos de chuvas espalham-se por trás da barreira formando um terraço como proteção do Vetiver. Há utilização para proteção de encostas, proteção contra erosão nas mais diversas localidades e necessidades. As raízes do Vetiver, apesar de resistentes, são muito finas, fato este que propicia alta proliferação de fungos e bactérias permitindo assim, a absorção de metais pesados e contaminantes (TRUONG; VAN; PINNERS, 2008).

Neste sentido, o presente trabalho teve por objetivo avaliar, por meio de experimentação laboratorial, o potencial fitorremediador do Capim Vetiver no tratamento de solo tropical contaminado com o metal Zinco presente em chorume proveniente de aterro sanitário.

\section{METODOLOGIA}

\subsection{Desenho experimental}

O contaminante utilizado foi chorume, proveniente de aterro sanitário, contendo $27,5 \mathrm{mgL}^{-1}$ de Zinco, elemento cujo valor máximo permitido pela legislação (CONAMA 430/11) para lançamento de efluente é de $5,0 \mathrm{mgL}^{-1}$. Considerando a possibilidade de que a utilização de chorume bruto pudesse ser letal as plantas (Broca, comunicação pessoal) optou-se por utilizar uma solução de rega com o metal em concentração final equivalente a $0,560 \mathrm{mgL}^{-1}$ e fator de correção igual a 5,455.

Para o estabelecimento dos sistemas de estudo (sistema controle e contaminado), foram utilizadas 28 mudas de Capim Vetiver, as quais foram introduzidas em um recipiente de 1000 litros. Para avaliar o potencial fitorremediador desta planta, o processo de contaminação do solo foi estabelecido por meio de regas periódicas (20 litros de solução contaminante introduzidos em 04/09/18 e 20/09/18) na proporção de 3:17 (3 litros de contaminante para 17 litros de água), nas duas primeiras regas e 5:15 (5 litros de contaminante para 15 litros de água introduzidos em 05/10/18) na última rega. O sistema de estudo ficou exposto às condições climáticas e foi implementado junto ao Viveiro de Mudas da Univap (Centro de Estudos da Natureza/Fazendinha), conforme figura 1. 
Figura 1 - Mudas transplantadas para o sistema de estudo em 27 de agosto de 2018.

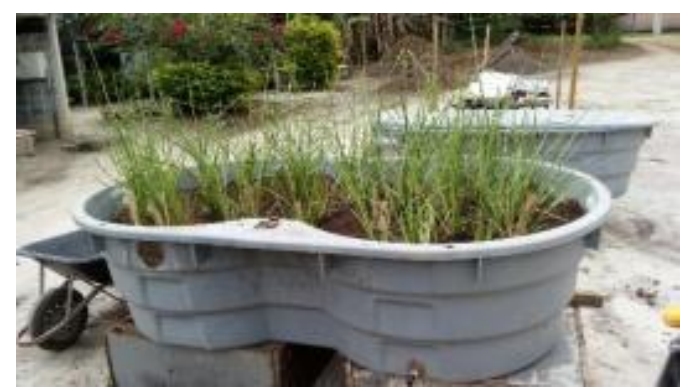

Fonte: Os autores.

\subsection{Plantio}

As mudas do Capim Vetiver foram adquiridas da empresa onde as mudas são produzidas, Alfa Proteção Ambiental, com sede no Sítio Nossa Senhora de Fátima, S/N - Bairro Olaria - Consolação/MG.

Foram adquiridas 110 mudas de Vetiver em raízes nuas, conforme figura 2, sendo que estas foram depositadas em baldes com água para minimizar/eliminar o processo de desidratação (figura 3) e posteriormente introduzidas em sacos plásticos de 17x22cm com capacidade suporte de $1 \mathrm{~kg}$ de solo. As mudas apresentaram folhas com comprimento médio de $25 \mathrm{~cm}$ e raiz com $5 \mathrm{~cm}$ de comprimento médio. O substrato de plantio foi preparado a partir de amostras de solo de barranco, areia e nutrientes (NPK) na proporção de 10:10:10 (Nitrogênio: Fósforo: Potássio).

Figura 2 - Mudas de Capim Vetiver em raízes nuas.

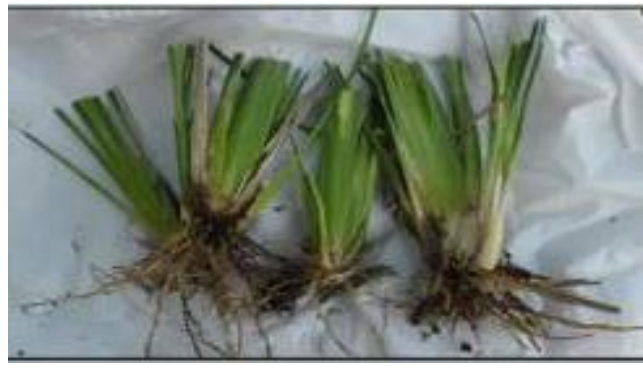

Fonte: Os autores.
Figura 3 - Mudas de Capim Vetiver em raízes nuas imersas em água.

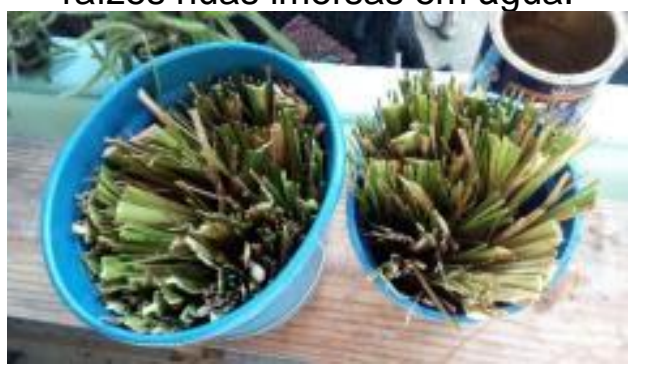

Fonte: Os autores.

As figuras 4 e 5 apresentam a preparação do substrato em sacos plásticos e posterior introdução das mudas. As figuras 6 e 7 mostram o desenvolvimento das mudas de Vetiver ao longo de quatro semanas após serem introduzidas em saquinhos, período este que garantiu adaptação das mesmas no ambiente de estudo. 
Figura 4 - Preparação do solo em saquinhos para plantio das mudas.

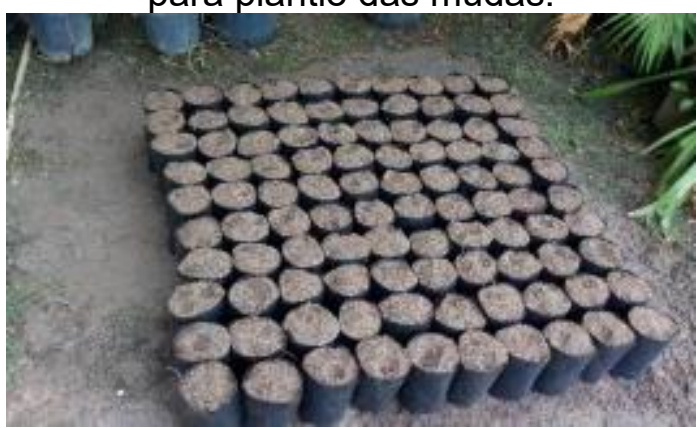

Fonte: Os autores.

Figura 6 - Mudas plantadas em saquinhos após 25 dias.

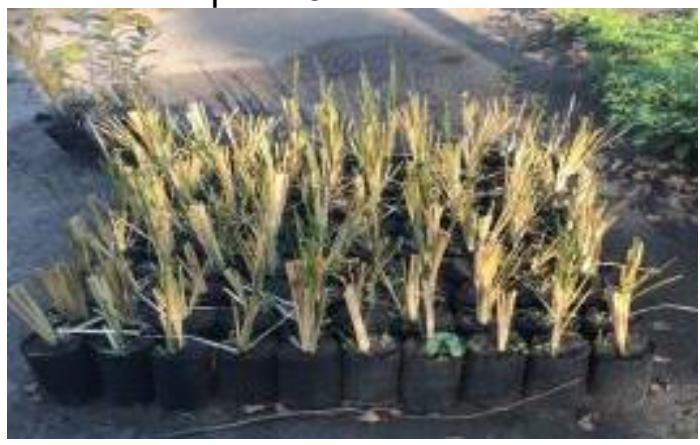

Fonte: Os autores.
Figura 5 - Mudas plantadas em saquinhos plásticos.

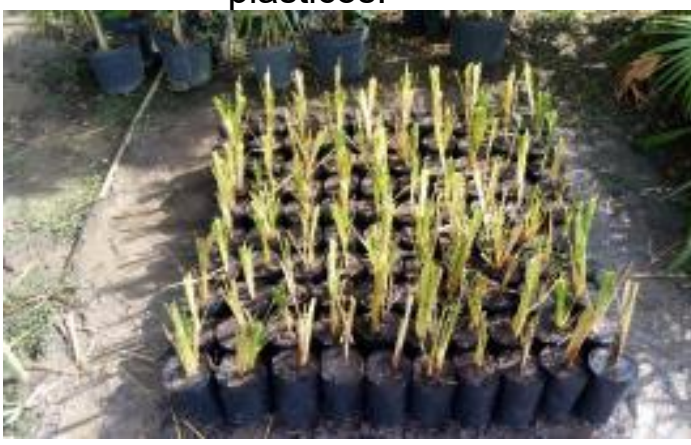

Fonte: Os autores.

Figura 7 - Desenvolvimento das mudas.

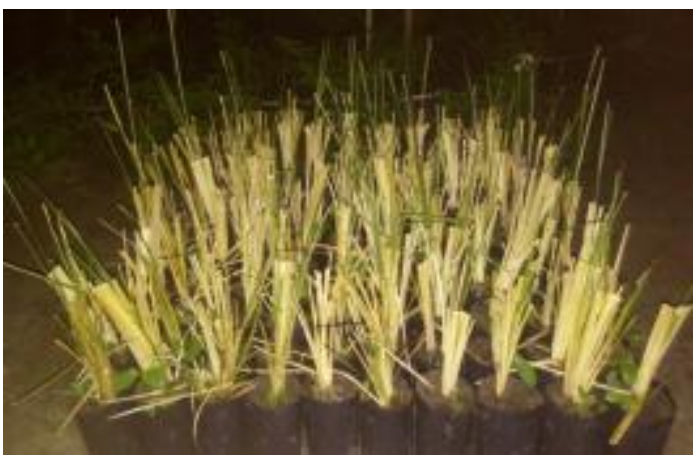

Fonte: Os autores.

Após 30 dias de adaptação, os ambientes de cultivo definitivo (sistema controle e a ser contaminado) foram preparados (figura 8). De forma a identificar a possivel contribuição de chuva junto ao sistema de estudo, instalou-se um pluviômetro junto ao mesmo (figura 9).

Figura 8 - Transplante das mudas para o sistema de cultivo.

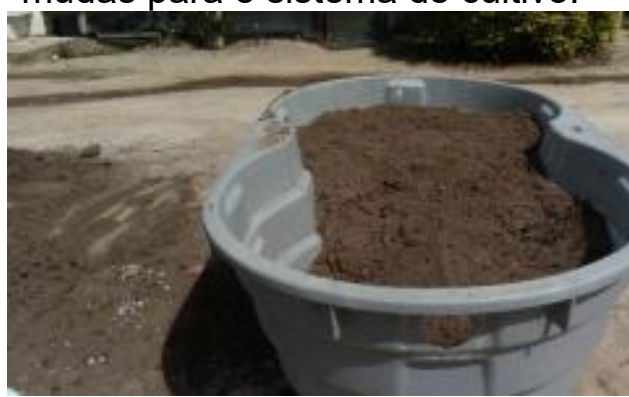

Fonte: Os autores.
Figura 9 - Primeira rega com chorume e instalação do pluviômetro.

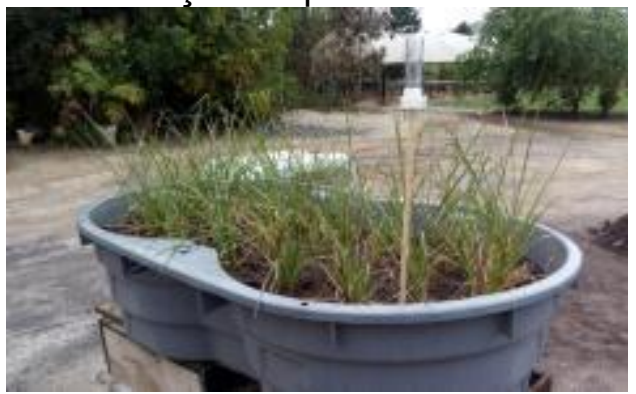

Fonte: Os autores.

A cada momento em que ambos os sistemas foram submetidos a rega, uma planta de Vetiver foi recolhida com a finalidade de avaliar o desenvolvimento da vegetação quanto ao comprimento das raízes e folhagem. A partir destes dados, foi calculada a razão raiz/folha para cada tratamento e ao longo do tempo (a cada duas semanas); 
posteriormente, os dados foram transpostos para a forma gráfica, juntamente com funções de ajuste, com o auxílio do programa Origin 7.5.

\subsection{Determinação de metais pesados}

\subsubsection{Amostras biológicas}

A fim de avaliar a presença de metais pesados nos tecidos do capim Vertiver, foram coletadas duas amostras, sendo uma proveniente do sistema controle e a segunda proveniente do sistema contaminado (figura 10). Essas amostras foram lavadas em água corrente e secas com papel toalha. Foram pesados $10 \mathrm{~g}$ de raiz, assim como $10 \mathrm{~g}$ de folhagens, oriundos de cada sistema de estudo os quais foram expostos à temperatura de $70^{\circ} \mathrm{C}$ durante 3 dias para secagem, conforme figura 11.

Figura 10 - Mudas retiradas do sistema contaminado com chorume.

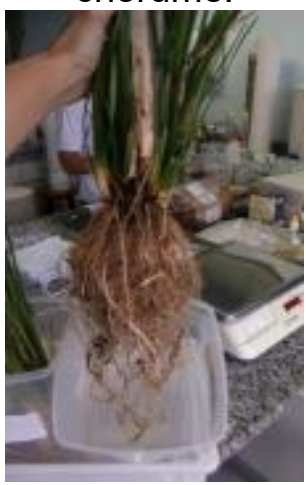

Fonte: Os autores.
Figura 11 - Amostras durante secagem na estufa a $70^{\circ} \mathrm{C}$ por três dias.

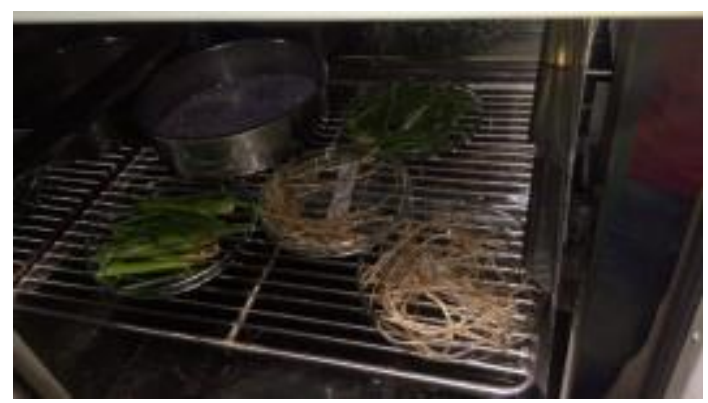

Fonte: Os autores.

Após o procedimento da secagem, as amostras secas foram trituradas e armazenados em potes plásticos de $70 \mathrm{ml}$, conforme figura 12. Para a avaliação da presença de metais pesados (Zinco) via espectroscopia de absorção atômica, adicionou-se às amostras de raiz e folhagem, $10 \mathrm{ml}$ de solução de $\mathrm{H}_{2} \mathrm{SO}_{4} 0,025$ mol.L ${ }^{-1}$, sendo as mesmas aquecidas a $180^{\circ} \mathrm{C}$ por 3 horas (figura 13).

Figura 12 - Amostras trituradas.

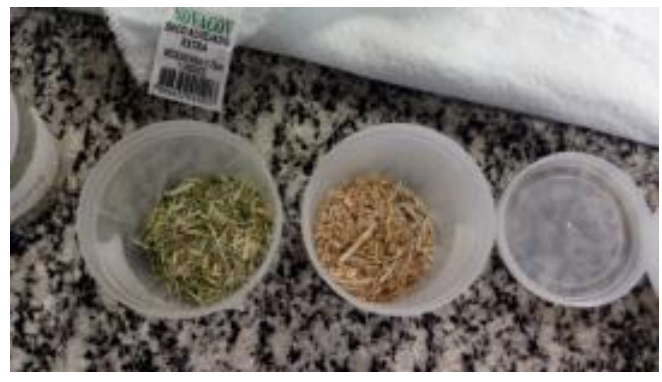

Fonte: Os autores.
Figura 13 - Amostras de solo sendo aquecidas em solução $\mathrm{H}_{2} \mathrm{SO}_{4}$.

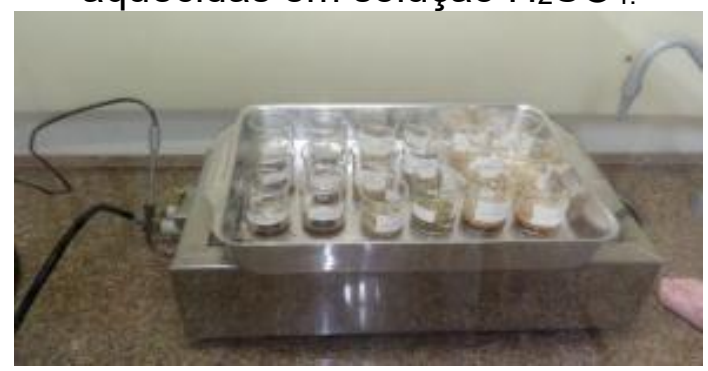

Fonte: Os autores. 
Após este procedimento, as amostras foram filtradas em papel de filtro $45 \mu \mathrm{m}$, sendo o filtrado resultante armazenado em frasco plástico limpo e seco com capacidade de 70ml (UNIVERSIDADE DE SÃO PAULO, 2015).

\subsubsection{Amostras de solo}

A determinação da quantidade de solo necessária para a realização das análises em espectroscopia de absorção atômica foi estabelecida a partir do estabelecimento da densidade do solo, conforme Tabela 1.

Tabela 1 - Cálculo da densidade do solo utilizado para o plantio das mudas de Vetiver.

\begin{tabular}{ccccc}
\hline Solo & Massa $(\mathrm{g})$ & Volume $\left(\mathrm{cm}^{3}\right)$ & Cálculo & Resultado \\
\hline Úmido & 356 & 190 & Ds $=\mathrm{m} / \mathrm{v}$ & $\mathrm{Ds}=0,4 \mathrm{~g} / \mathrm{cm}^{3}$ \\
Seco* $^{*}$ & 278 & 190 & & \\
\hline
\end{tabular}

*24 horas em estufa a $105^{\circ} \mathrm{C}$

Fonte: Os autores.

Assim, $5 \mathrm{~cm}^{3}$ de solo fino, seco, macerado e peneirado em peneira mesh $180 \mu \mathrm{m}$ (figura 14) foram transferidos para béquers de $50 \mathrm{ml}$, aos quais foram adicionados $10 \mathrm{ml}$ de solução e $\mathrm{H}_{2} \mathrm{SO}_{4} 0,025$ mol. $\mathrm{L}^{-1}$, e posteriormente aquecidos a $180^{\circ} \mathrm{C}$ durante 3 horas (conforme figura 18). O material resultante foi filtrado em papel filtro de $45 \mu \mathrm{m}$ e armazenado em frasco plástico limpo e seco com capacidade de 70ml (UNIVERSIDADE DE SÃO PAULO, 2015).

Figura 14 - Amostras trituradas e prontas para a digestão.

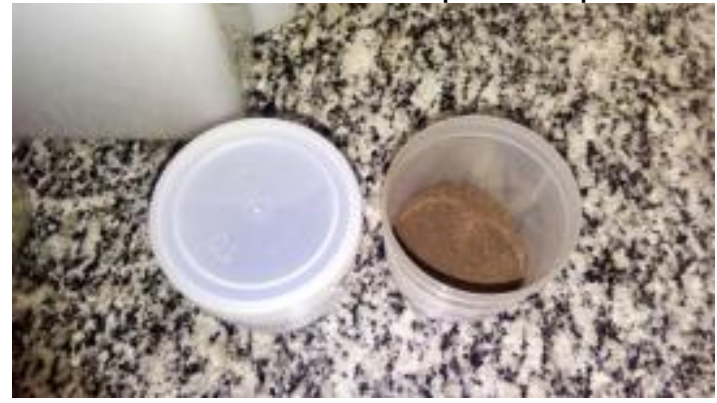

Fonte: Os autores.

\subsubsection{Amostras de lixiviado}

Para a análise da água de lixiviação, proveniente de ambos os sistemas, utilizouse uma alíquota de $50 \mathrm{ml}$ aos quais foram adicionados $10 \mathrm{ml}$ de solução de $\mathrm{H}_{2} \mathrm{SO}_{4}$ 0,025 mol. $\mathrm{L}^{-1}$, sendo aquecidos a $180^{\circ} \mathrm{C}$ durante 3 horas, conforme estabelecido para amostras biológicas e de solo. Ao final deste processo, o material resultante foi filtrado em papel filtro de $45 \mu \mathrm{m}$ e armazenado em frasco plástico limpo e seco com capacidade de 70ml (UNIVERSIDADE DE SÃO PAULO, 2015).

\subsubsection{Curva de calibração}


Para se estabelecer a curva de calibração do Zinco via espectroscopia de absorção atômica, foram utilizadas as soluções padrões conforme concentrações apresentadas na tabela 2. Todas as análises foram realizadas em Espectrômetro de Absorção Atômica marca Perkin Elmer AA200.

Tabela 2 - Solução padrão utilizada para a análise em espectrometria de absorção atômica

\begin{tabular}{ccccc}
\hline Substância & $\begin{array}{c}\text { Concentração } \\
(\mathrm{mg} / \mathrm{g})\end{array}$ & $\begin{array}{c}\text { Concentração } \\
(\mathrm{mg} / \mathrm{g})\end{array}$ & $\begin{array}{c}\text { Concentração } \\
(\mathrm{mg} / \mathrm{g})\end{array}$ & $\begin{array}{c}\text { Concentração } \\
(\mathrm{mg} / \mathrm{g})\end{array}$ \\
\hline $\mathrm{Zn}$ & 0,0007 & 0,0005 & 0,0003 & 0,0001 \\
\hline
\end{tabular}

Fonte: Os autores.

\section{RESULTADOS E DISCUSSÃO}

\subsection{Avaliação do desenvolvimento da Vetiver}

A tabela 3 e os gráficos 1 e 2 apresentam os resultados obtidos para a avaliação do desenvolvimento de raízes e folhagem de Capim Vetiver ao longo de 45 dias, em solo isento de contaminação e solo contaminado. O gráfico 3 mostra razão folha/raiz para cada tratamento e ao longo do tempo, juntamente com funções de ajuste.

Tabela 3 - Resultados obtidos na avaliação das raízes e folhas das mudas de controle e contaminadas ao longo do tempo.

\begin{tabular}{lcccc}
\hline & \multicolumn{2}{c}{ Controle (Água) } & \multicolumn{2}{c}{ Chorume } \\
\hline & Raiz $(\mathrm{cm})$ & Folhas $(\mathrm{cm})$ & Raiz $(\mathrm{cm})$ & Folhas $(\mathrm{cm})$ \\
\hline $04 / 09 / 2018$ & 23 & 70 & 20 & 70 \\
$20 / 09 / 2018$ & 28 & 90 & 28 & 90 \\
$05 / 10 / 2018$ & 30 & 110 & 30 & 100 \\
$20 / 10 / 2018$ & 40 & 128 & 50 & 120 \\
\hline
\end{tabular}

Fonte: Os autores.

Gráfico 1 - comparativo das medidas das raízes em 3 períodos $(15,20$ e 30 dias após o plantio).

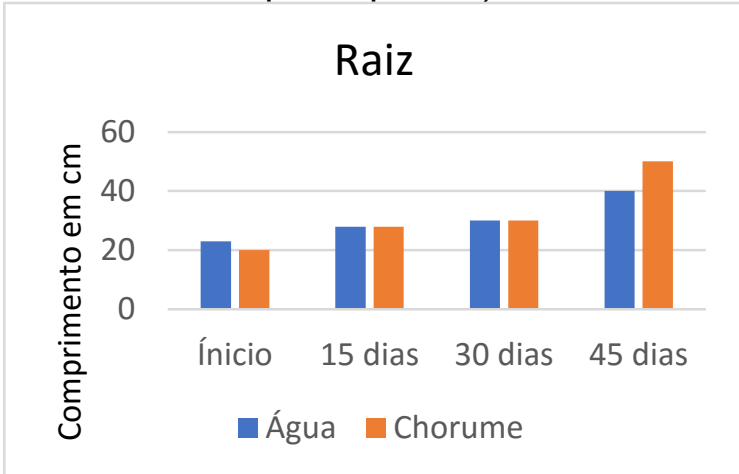

Fonte: Os autores.
Gráfico 2 - comparativo das medidas das folhas em 3 períodos (15, 20 e 30 dias após o plantio).

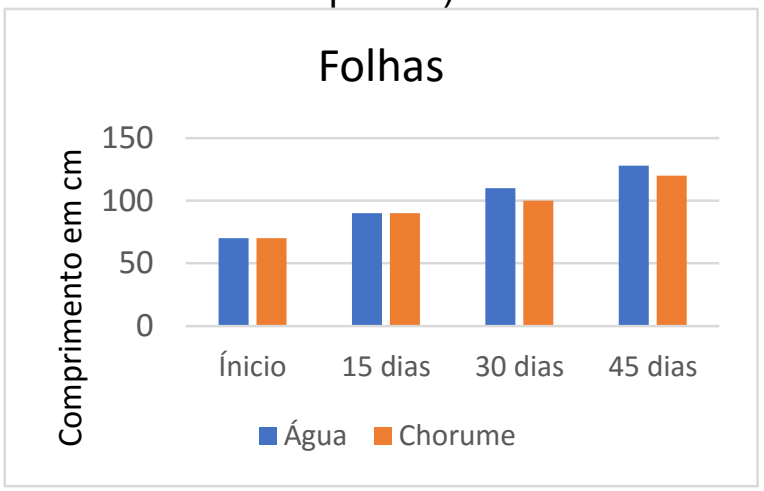

Fonte: Os autores. 
Gráfico 3 - Razão folha/raiz para cada tratamento, em função do tempo.

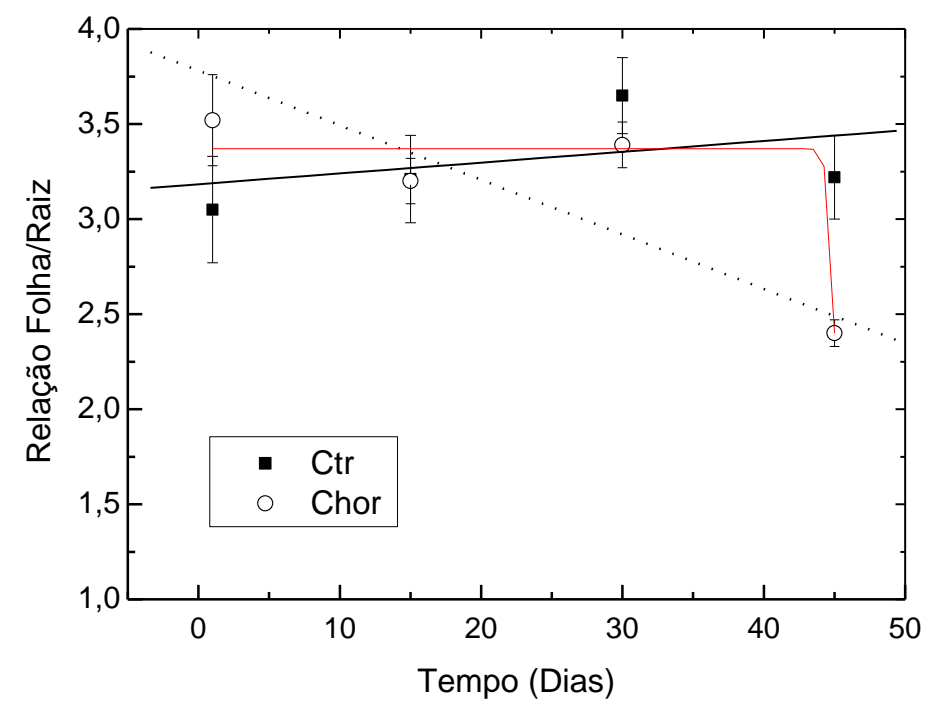

Fonte: Os autores.

A análise conjunta dos gráficos acima, permite observar que o desenvolvimento das raízes e folhagens foi praticamente homogêneo em ambos os sistemas de tratamento. Apenas uma pequena diferença foi observada quanto ao crescimento das raízes onde, após 45 dias de experimentação, o sistema radicular das plantas expostas ao chorume se desenvolveu mais do que a exposta em água, levando a uma queda na relação folha/raiz para as amostras com chorume; no entanto, esta queda só se revela para tempos superiores a sete semanas, e não é linear. Tal fato pode ser explicado pela função especializada das raízes em captar a solução nutritiva do solo para os processos fisiológicos da planta. Assim, a "solução nutritiva" representada pelo chorume pode ter oferecido estimulo positivo mais evidenciado ao desenvolvimento do sistema radicular ao longo do período de estudo.

A inspeção visual das plantas, ao longo do experimento, indicou que o chorume utilizado não foi tóxico para o cultivo desta espécie, uma vez que as mudas mantiveram coloração normal ao longo do período de estudo e o desenvolvimento das mesmas, no que se refere as raízes, foi igual ou maior que as mantidas no sistema controle e, no que se refere as folhas o desenvolvimento foi praticamente igual.

\subsection{Avaliação da concentração de metais pesados}

Os gráficos 4 e 5 apresentam os valores de zinco presentes nas amostras de solo, raízes e folhas de Vetiver e lixiviado, respectivamente, ao longo do período de estudo (45 dias). 
Gráfico 4 - Concentração de Zinco $\left(\mathrm{mgL}^{-1}\right)$ presente em amostras de raiz, folhas e no solo provenientes de sistemas controle e contaminados.

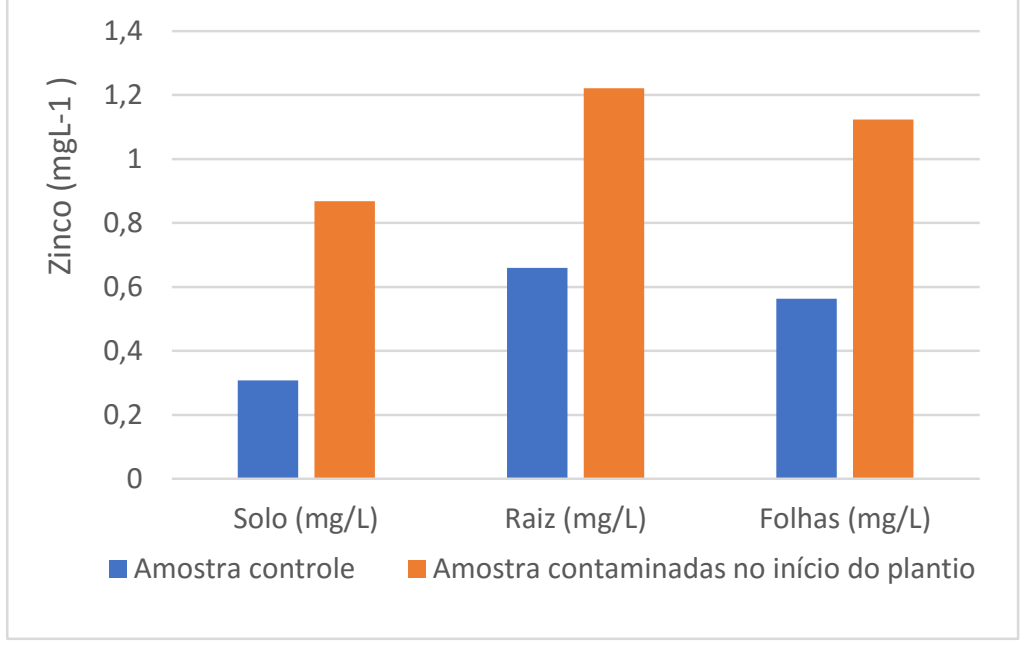

Fonte: Os autores.

Gráfico 5 - Concentração de Zinco $\left(\mathrm{mgL}^{-1}\right)$ presente em amostra de água resultante do processo de lixiviação no sistema tratado com chorume.

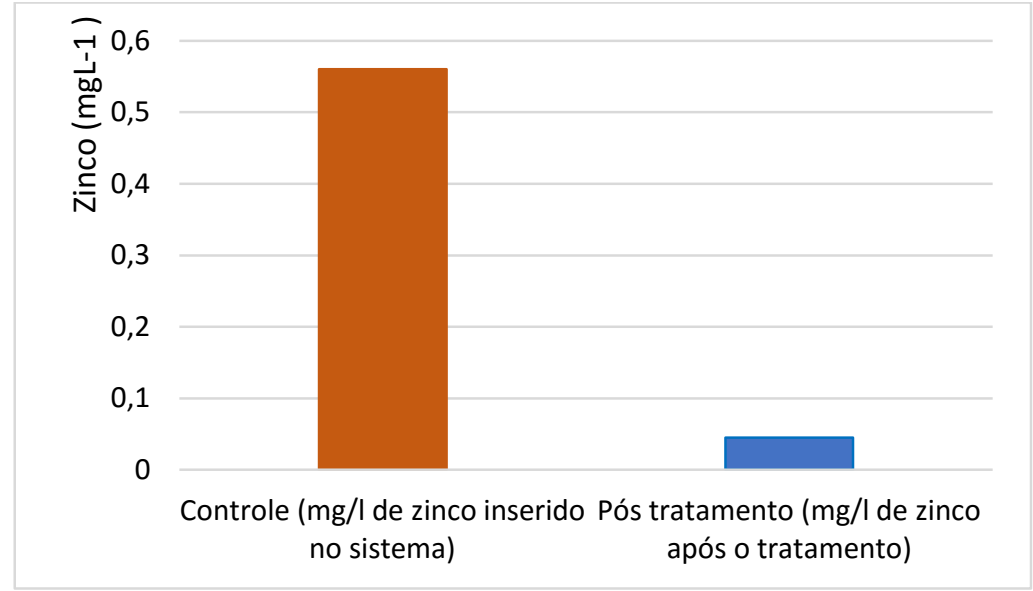

Fonte: Os autores.

Tabela 5 - Concentração de Zinco verificado ao final do experimento $\left(\mathrm{mgL}^{-1}\right)$

\begin{tabular}{cccccc}
\hline & Raiz & Folha & Solo & Lixiviado & Contaminação após 45 dias \\
\hline (A) Controle & 0,66 & 0,56 & 0,34 & 0,00 & \\
(B) Contaminado & 0,70 & 0,74 & 0,39 & 0,05 & \\
(B - A) & 0,04 & 0,18 & 0,05 & 0,05 & 0,32 \\
\hline
\end{tabular}

Fonte: Os autores. 
Tabela 6 - Concentração de Zinco verificado ao final do experimento (\%)

\begin{tabular}{cccc}
\hline & Raiz & Folha & Total \\
\hline (A) Controle & 0,66 & 0,56 & 1,22 \\
$\begin{array}{c}\text { (B) Contaminado } \\
\text { (B - A) }\end{array}$ & 0,70 & 0,74 & 1,44 \\
\hline $\begin{array}{c}\text { Concentração de } \\
\text { Zinco após 45 } \\
\text { dias (\%) }\end{array}$ & 7,86 & 0,18 & 0,22 \\
\hline
\end{tabular}

Fonte: Os autores.

Truong, Van e Pinners (2008), ao avaliar a espécie em questão no fitorremediador de águas residuais, observou que brotos e raízes adsorveram $40 \%$ da concentração total de Zinco foi $40 \%$ evidenciando que esta espécie apresenta alta resistência ao sistema contaminado bem como uma elevada eficiência no tratamento deste tipo de metal pesado. Adicionalmente, segundo Santos (2012), foi possível observar a eficiência do capim Vetiver em sistemas alagados de tratamento de efluentes, demostrando 0 quanto essa gramínea é adaptável e pode ser usada em diferentes tratamentos, sejam em meio alagado ou meio seco.

No presente trabalho observa-se que, com apenas 45 dias de exposição ao contaminante, o capim Vetiver conseguiu remover do sistema $39,29 \%$ do zinco introduzido incialmente, corroborando os resultados obtidos por Truong, Van e Pinners (2008). Todavia, quando considerado o processo de fitorremediação em sistema aquático, Almeida (2011), observou, em um período de estudo de 5 dias, uma eficiência de absorção de Zinco pelo capim Vetiver equivalente a 93\%.

Segundo Tavares e Oliveira (2013), estudando diferentes espécies vegetais na fitorremediação de solos contaminados por metais pesados, o tempo de exposição das essências vegetais aos metais pesados quando superior a 50 dias, podem garantir maior eficácia no processo de fitorremediação. Em contrapartida, Santos (2012) sugere que seja adotado o manejo utilizando podas contínuas em períodos de crescimento, estimulando o desenvolvimento da biomassa, aumentando assim a porcentagem de eficiência no tratamento.

No processo de fitorremediação, os materiais tóxicos são inicialmente capturados pelas raízes e posteriormente são translocados para caules e folhas, onde ficaram armazenados.

Almeida (2011) observou, em um período de estudo de 5 dias, em ambiente aquático, maior concentração do elemento Zinco nas raízes do capim Vetiver. Segundo a autora, a translocação no tecido vegetal ocorre lentamente, o que justificaria as baixas concentrações de Zinco quantificadas nas folhas, em função do curto período experimental.

No presente, onde a espécie em questão foi introduzida em solo, relação inversa 
foi verificada, tendo sido possível observar um maior crescimento das raízes (gráfico 7), porém com menor concentração do metal absorvido neste sistema (7,86\%) (Tabela 6). Assim, diferentemente do observado por Almeida (2011), no que se refere ao tempo necessário para translocação, o tempo de 45 dias de exposição ao contaminante permitiu que este fosse transcolado e armazenado nas folhas da Vetiver, muito provavelmente, em função dos processos diferenciados de absorção que ocorrem nos sistemas solo e aquático.

Assim, considerando o sistema de cultivo aqui adotado, a utilização do capim Vetiver no processo de fitorremediação mostrou ser uma boa alternativa no tratamento de resíduos contendo Zinco e avaliações em período superiores a 45 dias devem ser levadas em consideração.

A engenharia ambiental e sanitária é uma área ampla e capaz de abranger diversos casos e situações, desde a criação de novas tecnologias, até o aprimoramento das que já existem. Dentro deste contexto, o mercado tem exigido cada vez mais formas de mitigação dos problemas deixados no meio ambiente, e que não causem tantos impactos ao mesmo. A fitorremediação é uma estratégia que vem sendo utilizada, todavia ainda não é reconhecida como uma forma de tratamento considerável e eficaz pelos órgãos reguladores de metodologias uma vez que a destinação final do produto contendo os contaminantes ainda não é bem estabelecida.

\section{CONCLUSÃO}

A espécie em estudo, o capim Vetiver (Vetiveria zizanioides (L.) Nash.), ao longo de 45 dias, mostrou-se eficaz no tratamento de solo contaminado, em especial na remoção do metal pesado Zinco. Todavia, considerando que o efluente em questão é um material complexo, de composição altamente diversificada, novas avaliações utilizando o capim Vetiver devem ser estabelecidas a fim de elucidar melhor a utilização deste elemento no tratamento de chorume. Em particular, a partir dos estudos da razão folha/raiz, propõe-se que futuros estudos empreguem avaliações a intervalos de tempo menores (semanais), permitindo avaliar com maior detalhamento a ocorrência ou não de eventual desbalanceamento entre o desenvolvimento da raiz e o das folhas.

\section{REFERÊNCIAS}

ALMEIDA, E. A. P. Avaliação do potencial da espécie Vetiveria zizanioides na fitorrremediação de metais-traço presentes em ambientes aquáticos. 2011. $79 \mathrm{f}$. Dissertação (Mestrado em Saneamento, Meio Ambiente e Recursos Hídricos) Universidade Federal de Minas Gerais, Belo Horizonte.

BARRETO, A. S. Seleção de macrófitas aquáticas com potencial para remoção de metais-traço em fitorremediação. 2010. 81 f. Dissertação (Mestrado em Saneamento, Meio ambiente e Recursos Hídricos) - Universidade Federal de Minas Gerais, Belo Horizonte, 2010. 
COUTINHO, P. W. R. et al. Alternative Soil Remediation: Bioremediation and Phytoremediation. Nucleus, v. 12, n. 1, p. 59-68, 2015.

http://dx.doi.org/10.3738/1982.2278.1400

LAMEGO, Fabiane Pinto; VIDAL, Ribas Antonio. Fitorremediação: plantas como agentes de despoluição? Pesticidas: Revista de Ecotoxicologia e Meio Ambiente, [S.I.], v. 17, dez. 2007. Disponível em:

https://revistas.ufpr.br/pesticidas/article/view/10662. Acesso em: 10 fev. 2020.

LEAL, E. F. et al. Fitoremediação de chumbo pelas espécies Vetiver (Vetiveria zizanioides L), Feijão de porco (Canavalia ensiformis L.), e Singônio (Syngonium angustatum. In: CONGRESSO BRASILEIRO DE CIÊNCIA DO SOLO, 36., 2013, Florianópolis. Anais. Florianópolis, 2013. p. 1 - 4. Disponível em:

http://eventosolos.org.br/cbcs2013/anais/arquivos/2760.pdf. Acesso em: 28 abr. 2018.

MONTEIRO, M. T. Fitorremediação de rejeito contaminado proveniente do Canal do Fundão, na Baía de Guanabara-RJ. Rio de Janeiro, 2008. Tese (Doutorado em Engenharia Civil) - Universidade Federal do Rio de Janeiro, Rio de Janeiro, 2008.

SANTOS, L. M. Avaliação do desenvolvimento e da eficiência do Capim Vetiver (Chrysopogon zizanioides) em sistemas híbridos de alagados construídos. 2012. 79 f. Dissertação (Mestrado em Engenharia Civil e Ambiental) - Universidade Estadual Paulista, Bauru, 2012. Disponível em:

https://repositorio.unesp.br/bitstream/handle/11449/98303/mirandasantos I me bauru. pdf? sequence=1\&isAllowed=y. Acesso em: 24 out. 2018.

TAVARES, S. R. de L.; OLIVEIRA, Shirlei Aparecida de. Avaliação de espécies vegentais na fitorremediação de solos contaminados por metais pesados. In: HOLOS, 29., 2013, Rio de Janeiro. Proceedings. Rio de Janeiro: Holos, 2013. v. 5, p. 80 - 97. Disponível em: http://www2.ifrn.edu.br/ojs/index.php/HOLOS/article/view/1852/728. Acesso em: 15 out. 2018.

TRUONG, P.; VAN, T. T.; PINNERS, E. Sistema de aplicação Vetiver: manual de referência técnica. 2. ed. Pomerode: Rede Internacional de Vetiver., 2008. 116 p.

UNIVERSIDADE DE SÃO PAULO. Escola Superior de Agricultura Luiz de Queiroz (Org.). Manual de métodos: Disciplina: Química Inorgânica e Analítica. Piracicaba: Universidade de São Paulo, 2015. Disponível em:

http://www.esalq.usp.br/departamentos/lce/arquivos/aulas/2015/LCE0108/marcos/Man ual de Metodos-Aula Pratica-LCE0108.pdf. Acesso em: 01 nov. 2018. 